\title{
Variantes de autor en la poesía impresa de Montemayor
}

\author{
JuAn MONTERO \\ Universidad de Sevilla
}

Título: Variantes de autor en la poesía impresa de Montemayor.

Resumen: En el contexto de la transmisión textual de la poesía del Siglo de Oro, Jorge de Montemayor es uno de los rarísimos autores que llevaron a cabo correcciones redaccionales en las sucesivas impresiones de sus versos a lo largo de su vida. En este trabajo se analizan algunos casos relacionados con la expresión de la espiritualidad en sus poemas tanto profanos como devotos.

Palabras clave: Montemayor, Imprenta, Variantes de autor, Espiritualidad.

Fecha de recepción: 2/4/2014.

Fecha de aceptación: 24/6/2014.
Title: Author's Variants in Montemayor's Printed Poetry.

Abstract: In the context of the textual transmission of Spanish Golden Age poetry, Jorge de Montemayor is one of the very few authors who made editorial corrections in the successive editions of his poems throughout his life. In this article, I analyse some instances of these corrections related to the expression of spirituality in both his profane and devotional poems.

Key words: Montemayor, Printing, Author's variants, Spirituality.

Date of Receipt: 2/4/2014.

Date of Approval: 24/6/2014.

Como bien se sabe, la peculiar transmisión de los textos poéticos en el Siglo de Oro hace que sea difícil encontrar un terreno propicio para el tipo de estudio que aquí se propone. Si, en efecto, el número de poetas que imprimieron sus obras en vida fue relativamente escaso, mucho más 
lo fue el de aquellos que llegaron a verlas impresas más de una vez. Entre estos poquísimos tiene un lugar destacado Jorge de Montemayor.

Los datos relativos a la transmisión de los versos del lusitano los he expuesto en otros lugares, por lo que aquí voy a limitarme a recordar lo esen$\mathrm{cial}^{1}$. El grueso de su poesía está recogido en un cancionero que se desarrolló editorialmente en tres fases. La primera está representada por la edición conocida como Las obras, de la que se conocen tres impresiones íntegras en vida del autor (Medina del Campo, Guillermo Millis, ¿1552-1553?; Amberes, Iuan Lacio, 1554; Estella, Adrián de Amberes, 1556) y una parcial (Las obras de amores, Zaragoza, Esteban de Nágera, 1554) ${ }^{2}$. En la segunda fase, ese volumen da lugar a dos, uno con los versos profanos (Segundo cancionero, Amberes, Iuan Lacio, 1558) y otro con los devotos (Segundo cancionero spiritual, Amberes, Iuan Lacio, 1558); no es un mero cambio de presentación, sino que el corpus poético se ve transformado: se suprimen poemas, se añaden otros nuevos, se reordenan y se introducen cambios redaccionales en muchos de los que se mantienen de la fase precedente. La tercera fase, tras la prohibición de los versos devotos en el Index inquisitorial de 1559, está representada por el llamado Cancionero (Zaragoza, viuda

1 "Jorge de Montemayor, Cancionero", en Diccionario Filológico de la Literatura Española (siglos XVI y XVII). Textos y transmisión, dir. Pablo Jauralde Pou, Madrid, Castalia, 2010, pp. 704-716; y Jorge de Montemayor, Poesía selecta, ed. Juan Montero y Elizabeth Rhodes, Madrid, Castalia, 2012, pp. 19-29 ("El cancionero de Montemayor: proceso editorial").

2 Sobre la edición medinense, de la que se solo se conocen dos ejemplares mútilos de la sección devota (biblioteca de la Hispanic Society y Bayerische Staatsbibliothek), cf. Jaime Moll, "Sobre la historia de la primera edición de Las obras de Jorge de Montemayor", Voz y Letra. Revista de Literatura, 19, 2 (2008), pp. 3-8; sobre la zaragozana del 54, cuyo ejemplar único se conserva asimismo en la biblioteca de la Hispanic Society, cf. Juan Pérez de Guzmán y Boza, Marqués de Jerez de los Caballeros, "Unas papeletas bibliográficas", en Homenaje a Menéndez Pelayo en el año vigésimo de su profesorado. Estudios de erudición española, Madrid, Victoriano Suárez, 1899, II, pp. 639-644; sobre la estellesa, también conservada en ejemplar único (Biblioteca Nacional, Madrid), cf. Mercedes Dexeus, "La primera edición española del Cancionero de Montemayor con las obras devotas de Juan Fernández de Heredia", Trabajos de la Asociación Española de Bibliografía, II (1998), pp. 277-82. La colación de estas ediciones hace ver que la medinense sirvió como modelo, por separado, a la de Amberes y a la zaragozana; a su vez, la antuerpiense sirvió de modelo a la de Estella. 
de Bartolomé de Nágera, 1562, y varias ediciones más), que deriva (aunque no es mera copia) del Segundo cancionero antuerpiense; se trata ya de una edición póstuma, cuyas variantes no deben ser consideradas de autor.

Como decía poco antes, la intervención del autor sí es segura en el corpus de poemas comunes entre Las obras y las dos colecciones de 1558. En el prólogo "Al lector" del Segundo cancionero hay una declaración al respecto, que deja amplio margen a la interpretación:

Un libro mío se imprimió habrá algunos años con muchos yerros, ansí de parte mía como de los impresores, y porque la culpa toda se me ha atribuido a mí, a este segundo libro junté las mejores cosas del primero, y las enmendé; y lo mismo se hace en el segundo de las de devoción que ahora se imprimió, por lo cual merezco de la pasada culpa ser perdonado ${ }^{3} .$.

Se habla ahí de enmiendas a los yerros del autor y de los impresores. La declaración es interesante porque deja ver que no se trata de la mera eliminación de erratas sino de un trabajo más delicado de autocorrección. Para entender esto habrá que recordar un par de cosas. La primera, que un pasaje de uno de los poemas devotos de Las obras, concretamente La pasión de Cristo, fue condenado como herético por un tal Juan de Alcalá, en un sonado intercambio de sátiras con el lusitano ${ }^{4}$. Y segundo, en un sentido más amplio, que Montemayor parece ser muy consciente de que sus versos se movían en una línea delgada entre la ortodoxia y la heterodoxia religiosa, justamente en el momento en que esa línea iba a convertirse en muralla infranqueable. Por eso se cura ya en salud y afirma haber enmendado sus yerros ${ }^{5}$.

3 Segundo cancionero, ff. A4v-A5r.

4 Juan Montero, "Viejos y nuevos datos sobre la controversia poético-teológica entre Juan de Alcalá y Jorge de Montemayor", Nueva Revista de Filología Hispánica, LIII (2005), pp. 163-179.

5 De manera análoga, afirma en la dedicatoria del Segundo cancionero spiritual: "Después de haber, muy magnífico Señor, trabajado muchos días en este libro y comunicado lo que en él hay con mucho teólogos, así en estos estados de Flandes como en España, especialmente en el colegio de San Gregorio de Valladolid -que así en ciencia como en ejemplo ha siempre en nuestra Europa florecido-y después de haber enmendado algunas obras que del primero a él ayunté -cosas que no se pueden llevar a cabo sin grande trabajo de espíritu..."; la dedicatoria completa puede 
Ahora bien, no vayamos a pensar por ello que tales enmiendas afecten exclusiva o preferentemente a los poemas devotos. En ese dominio, el cambio más sustancial entre 1553 y 1558 es, desde mi punto de vista, la supresión de la paráfrasis sobre el Padrenuestro, un largo poema inspirado en el rigorismo de Savonarola. No, los cambios son tan abundantes y aun más en los versos amorosos, lo que indica finalmente que su origen está en una voluntad autorial de revisión, como podrá comprobar el lector interesado consultando el aparato crítico de la Poesía selecta ya citada. En estas páginas me limitaré, por ello, a espigar algunos ejemplos ilustrativos de esa práctica correctora, enriqueciéndolos con algunos comentarios. Eso sí: los ejemplos seleccionados tienden a mostrar que dicho afán revisionista se vio reforzado o condicionado en algunos casos por el escrúpulo que el lusitano sintió después de 1553 en lo atinente a la expresión de su espiritualidad.

\section{UNA GLOSA, UN SONETO, UNA EPÍSTOLA}

Montemayor, al igual que alguno de sus coetáneos (pienso, por ejemplo, en Gregorio Silvestre), actualiza en su poesía amorosa la tradición cancioneril de contaminar entre sí la expresión del amor divino y el profano. Esta mescolanza propicia algunos de los cambios textuales que se aprecian en la edición de $1558(S)$ con respecto a Las obras $(M)^{6}$. Veamos algunos casos.

La glosa de Justa fue mi perdición (inc.: "Ser ganado el que perdió”) presenta en $S$ cierto número de variantes que indudablemente son correcciones del autor ${ }^{7}$. De ellas, me interesa destacar en concreto una:

leerse en Jorge de Montemayor, Poesía completa, ed. Juan Bautista de Avalle-Arce, con la colaboración de Emilio Blanco, Madrid, Fundación José Antonio de Castro, 1996, pp. 728-729.

6 Prescindo de las demás ediciones de Las obras porque carecen de relevancia textual en el punto que aquí me interesa: las variantes redaccionales.

7 Por ejemplo: 24 jamás le puede $S$ : nunca le pudo $M / / 64$ y aunque veis que está rendida $S$ : y aunque de mí se despida $M / / 79$ a dolor tan grave y duro $S:$ al dolor que me procuro $M / / 96$ que es la vida estar difunto $S$ : que vivo aunque esté defunto 
Todo el merecer que veis en todas, de vos le cobran; vos sola las mantenéis con las migajas que sobran de lo que vos merecéis;

que en ver vuestra perfición sola sin comparación tristes y invidiosas viven, y aquí se ve mi razón, pues la pasión que reciben satisfizo mi pasión (45-55).

La copla, que trata el tópico de que la amada reúne todas las perfecciones que están repartidas entre otras, presenta esta variante:

53 se ve mi razón $S$ : está mi salvación $M$

Si buscamos una motivación para el cambio, no aparece otra que la de eliminar un término (salvación) que tiene una fuerte connotación religiosa, subrayada además por la rima con pasión. Sea por iniciativa propia o a sugerencia de alguien, Montemayor pudo pensar que el texto de $M$ podía ser percibido como una trivialización inadecuada de tales términos. Es dudoso, por lo demás, que el retoque suponga una mejora poética, ya que resta patetismo a la expresión afectiva. Lo mismo ocurre, a mi juicio, en la copla siguiente:

Yo no puedo estar quejoso

de verme tan bien perdido, pues fue don maravilloso que siendo de vos vencido quedase tan vitorioso;

que si el alma está vencida recibe gloria subida en vuestra contemplación, y aunque veis que está rendida,

$M / / 102$ y aun hizo con su poder $S$ : y aun le hizo conceder $M$, etc.; cf. Poesía selecta, pp. $79-84$ y 434 . 
sola esta imaginación

es vitoria conocida. (56-66)

64 y aunque veis que está rendida $S:$ y aunque de mí se despida $M$

En la redacción de $M$, la hipérbole sacroprofana acaso podía entenderse como que, en el momento de su muerte, el amante sólo encontraba consuelo en la contemplación de la amada. Aunque el sentido sea otro (sencillamente, que el alma del amante vive en la amada), el cambio de $S$ parece destinado a eliminar la posible ambigüedad y, de paso, rebajar la carga religiosa de la copla.

Pasemos ahora al soneto "Quien no sabe de amor en mis concetos", que era el segundo en la dispositio editorial de la sección italianizante de Las obras, con algunos rasgos de soneto prologal. En $S$ perdió esa posición privilegiada y sufrió diversos retoques textuales, hasta quedar así:

Quien no sabe de amor en mis concetos no se entremeta y calle lo que viere; y el que sabe de amor o amor le hiere, lo fino verá en mí de sus efectos.

Venid, pues, amadores, que sujetos

estáis a lo que amor ordena y quiere, y en mí veréis que aquel que más sufriere, mejor lugar terná entre los perfectos.

No está el descanso, no, en vivir quieto el ánimo, ni está en buena fortuna, 10 si el hombre a un buen amor no está sujeto.

Y sepa cierto aquel que amor repugna, ora sea rico, fuerte o sea discreto, que no hay do no hay amor bondad alguna ${ }^{8}$.

La variante que me interesa destacar es:

8 Poesía selecta, pp. 134 y 436 (aparato). Además de la que se comenta a continuación, el poema presenta estas variantes: 2 viere $S$ : oyere $M / / 3$ y el que $S:$ y si $M / / 11$ a un buen amor $S$ : al firme amor $M / / 12$ Y $S$ : Pues $M / /$ cierto $M$ : cierta $S$ [Error de $S$. 


\section{3 rico $S$ : casto $M$}

El leve cambio se vuelve plenamente significativo a la luz del v. 14, cuyo subtexto paulino (Corintios, I, 13) revela la doble lectura, profana y devota, del poema. De tal manera que casto bien podía entenderse como una alusión a la falta de caridad de los clérigos y frailes, por mucho voto de castidad que hubiesen hecho. La insistencia en la caridad como principio rector de la vida cristiana encajaba perfectamente en el discurso de los reformistas católicos, como fray Luis de Granada, pero por eso mismo estaba rodeado de un halo de disidencia que se materializó en las condenas del índice de 1559.

Por último, señalaré un caso localizado en la epístola amorosa “¡Ay Vandalina mía, quién pudiese!"9. Se produce en el terceto:

Aunque me mate ahora el mal de ausencia,
estoy a contemplarte tan sujeto
que acá te veo contino en mi presencia. (61-63)

63 que acá te veo contino $S:$ que yo te veo por fe $M$

En la primera redacción, la cogitatio o contemplación mental de la amada ausente queda vinculada a la $f e$ amorosa, idea que, trasladada al plano espiritual, no tiene nada de sospechosa. El problema radicaba quizá en la asociación entre la actitud meditativa y la visión en presencia del objeto mental, que podía interpretarse como alusiva a una experiencia visionaria o extática. A este escrúpulo se sumaban, por otra parte, razones métricas: el texto de $M$ o es hipométrico, o tiene un acento anómalo en la séptima sílaba, o conlleva una dialefa abrupta entre la sexta y la séptima. Sea como fuere, el hecho es que $S$ alivia la carga religiosa del terceto y proporciona una lectura más neutra del tópico amoroso.

9 Poesía selecta, pp. 154 y 439 (aparato). Otras variantes del poema: 2 de manera $S$ : en tal manera $M / / 15$ en sí no tiene $S:$ no tiene en sí $M / / 18$ la $S:$ su $M / / 19$ alma propria $S$ : propria ánima $M / / 22$ aun $S$ : ya $M / / 28$ con el $S:$ yo con $M / / 33$ estoy con $S$ : tengo $M / / 57$ sobrehumano $S$ : soberano $M / / 73$ A qué piensas, señora $S$ : En fin, señora mía $M$. 


\section{Variantes iREDACCIONALES? EN EL "Soliloquio"}

La sección devota de Las obras se abre con un poema octosilábico de carácter penitencial en el que la voz poética se desdobla en dos, la del pecador y la de su conciencia que lo llama a enmendarse (inc. “¿Qué es esto? ¿Yo en qué me fundo, / en dormir o estar despierto?”). Su privilegiada posición indica que se trata de un poema relevante, y la transmisión de texto no hace sino confirmar esa idea. Además de estar presente en todas las impresiones de Las obras ${ }^{10}$, así como en el Segundo Cancionero spiritual ( $=S p$ ), aunque ya en séptima posición, lo encontramos impreso, con variantes, en un pliego que forma parte de la prehistoria editorial y textual del cancionero del lusitano: el Cancionero de las obras de devoción de Jorge de Montemayor, Burgos, Junta, $1552(=D)^{11}$. E incluso existe un testimonio manuscrito recogido en un cancionero religioso de mediados del XVI, el ms. B 2465 de la Hispanic Society of America $(=H)$, cuyas variantes podrían tener valor textual ${ }^{12}$.

10 Incluida la princeps de Medina del Campo. Aunque, como ya se ha dicho (n. 2), los dos ejemplares que hoy conocemos de ese libro están mútilos de la sección devota, es indudable que el poema estaba ahí recogido. La prueba nos la da la edición de Las obras de amores (Zaragoza, $1554=\mathrm{Z}$ ), en la que el "Soliloquio" se empleó para completar el último pliego; pues bien, como se verá, el texto que ahí se ofrece no puede derivar de la impresión antuerpiense de 1554, por lo que su modelo tuvo que ser el de la medinense.

11 Jean Dupont, "Un pliego suelto de 1552 intitulé: Cancionero de las obras de devoción de Jorge de Montemayor", Bulletin Hispanique, LXXV (1973), pp. 40-72. Describe el ejemplar único conocido, que se custodia en la Biblioteca Municipal de Besançon (Francia); cf. asimismo Antonio Rodríguez-Moñino, Nuevo diccionario bibliográfico de pliegos sueltos poéticos (siglo XVI), ed. corregida y actualizada por Arthur L.-F. Askins y Víctor Infantes, Madrid, Castalia, 1997, no 380.5; y Mercedes Fernández Valladares, La imprenta en Burgos (1501-1600), Madrid, Arco Libros, 2005, no 420.

12 Antonio Rodríguez-Moñino y María Brey Mariño, Catálogo de los manuscritos poéticos castellanos existentes en la biblioteca de The Hispanic Society of America (siglos XV, XVI, XVII), Nueva York, Hispanic Society of América, 1965, nº VII, 5. El ms. fue propiedad del Marqués de Jerez de los Caballeros. 
Las variantes que se producen en la transmisión impresa no tienen valor redaccional, pero sí sirven, como ya se ha apuntado, para demostrar que $Z$ deriva de $M$ y no de $A$. Sin entrar en detalles menores ${ }^{13}$, el locus determinante lo tenemos en el v. 33:

¿A qué hermano o a qué padre

me quejo? ¿Yo no soy yo?

Sí, y ante mí queja dó

de mí mismo y de la madre

que en chico no me ahogó. (30-35)

33 Sí, y ante mí queja dó $D S p$ : Sí, y ante mí que mi queja dó $A Z$

Es evidente que la hipermetría de $A Z$ tiene valor de error conjuntivo que debía figurar ya en $M$, de donde pasó a las demás ediciones de Las obras. Por su lado, la lección de SP no hace más que recuperar la que ya figuraba en $D$ y debe ser atribuida al propio Montemayor.

Las variantes aportadas por el manuscrito neoyorquino, por su lado, son más y requieren una valoración más detenida. Hay varias que son claramente errores de copia ${ }^{14}$. Otras tienen un alcance tan limitado que resulta difícil percibir en ellas una intencionalidad autorial; la prudencia crítica me lleva a tomarlas por simples variantes de transmisión ${ }^{15}$. Final-

13 Me refiero ahora a otras variantes de interés entre los impresos: 68 ya que muestras $D$ $Z S p$ : ya me muestras A [Error de $A$, que probablemente no figuraba en $M / / 98$ las sufrió muy como bueno $D S p$ : las sufrió como bueno $A Z$ [Error de $A Z$ que acaso ya figuraba en $M$, pero que también pudieron cometer cada uno por su cuenta // 100 quies $D Z S p$ [qui es $S p$ ] : quieres A [La escansión silábica demuestra que el error está en $A$; la lectura de $Z$ hace pensar que no figuraba en $M / / 110$ se va acostar [a costar] $D S p$ : se va a acostar $Z A$ [La lectura de $D$ y $S p$ supone una a embebida.

14 Como tales considero: 31 hermano o a qué padre $D A Z S p$ : padre o a qué madre $H$ [La rima madre se repite tres versos más abajo en $H / / 40$ a mí $D A Z S p$ : de mí $H$ [La lección de $H$ es agramatical // $61 \mathrm{Y}$ pues $D A Z S p$ : Pues $\mathrm{H}$ [Probable hipometría en $H / / 70$ lo dejo $D A Z S p$ : lo dejas $H$ [La lección de $H$ es agramatical. Además, los vv. 66-70 están copiados en $H$ fuera de su sitio, como penúltima semiestrofa del poema.

15 Son estas: 34 la madre $D A Z S p$ : mi madre $H / / 35$ en chico $D A Z S p$ : chico $H / /$ 59 de hacello $D A Z S p$ : en hacello $H / / 60$ de decillo $D A Z S p$ : en decillo $H / / 94$ ni $D A Z S p: y \sin H$. 
mente, queda un haz de lecciones de indiscutible relevancia textual. Veámoslas.

1. ¡Oh maldad clara y notoria, oh notoria falsedad, que al tiempo que tu bondad me amuestra y abre la gloria, cierre yo la voluntad! (26-30)

27 oh notoria $D A Z S p$ : no es notoria $H$

La lección de $H$ lleva a interpretar la frase como interrogativa, algo que encaja perfectamente en la retórica homilética del poema.

2. Y no fuera de tal arte cual siempre me conocí, pues siempre en mi mano vi el poder, aunque soy parte, para me juzgar a mí. (36-40)

38 pues siempre en mi mano vi $D A Z S p$ : ni echara menos así $H$

La lección de $H$ es plenamente aceptable y se integra bien en el decurso textual de la estrofa.

3. Luego ¿por qué no te mueves al Señor que siempre fue, que te dice: "Hombre sin fe, conoce tú que me debes: yo mismo te pagaré”? (46-50)

46 Luego $D A Z S p$ : Pues di $H$

Nuevamente, $H$ ofrece una lección del todo válida, coincidente con el arranque de una semiestrofa posterior: "Pues di, ¿cuándo, carne mía, / irás por carrera llana, / ya que muestras tanta gana?” (66-68). 
4. Conoce el divino pago

de Jesú de Nazaré,

y pues eres de su fe,

si puedes decir: "Yo hago",

nunca digas: "Yo haré". (76-80)

76 pago $D A Z S p$ : halago $H$

La lección de $H$ es válida desde el punto de vista léxico, pero seguramente incurre en hipermetría, a causa de la necesaria aspiración de la $h$ inicial ${ }^{16}$.

5. ¿Sabéis qué querría yo?

Subir do Cristo subió

sin angustia ni dolor:

baste las que él padeció.

Pues si él para subir

a su proprio reino pleno

las sufrió muy como bueno,

¿cómo tú sin las sufrir

quies subir a reino ajeno? (91-100)

95 baste las $D A Z S p$ : basta la $H$

98 las [la $H]$ sufrió muy como bueno $D S p H$ : las sufrió como bueno $A Z$ 100 quies [quieres $A$ ] subir a reino ajeno $D A Z S p$ : quieres subir al ajeno $H$

En este caso, lo más significativo es que las variantes tienen continuidad entre sí (las dos primeras) o se integran en un decurso textual amplio (la tercera). Ambos rasgos son indicio de una posible intervención autorial.

16 De hecho, lo habitual en Montemayor es la aspiración de esa misma $h$, como en el endecasílabo: "y, si esto me enfadaba, halagándome" (La Diana, ed. Juan Montero, pról. Juan Bautista de Avalle-Arce, Barcelona, Crítica, 1996, p. 35); en la traducción de Ausiàs March (1560): "mas temo amor que ahora me halaga", "tristeza me halaga, y es perdida" (Poesía completa, pp. 1138 y 1158). El sintagma divino halago estaba autorizado, entre otros, por Fray Luis de Granada: "Éste [hablando de sí mismo] nunca pudo ser atraído al bien con los halagos divinos, ni atemorizado con sus juicios" (Libro de la oración y meditación, ed. Álvaro Huerga, Madrid, FUE - Dominicos de Andalucía, 1994, p. 128). 
Si esta llegó a existir bajo la forma de un proceso de revisión textual, la colación externa lleva a pensar que, en principio, la versión manuscrita tendría que ser la primitiva, dado que tenemos una secuencia homogénea de testimonios impresos entre 1552 y 1558 avalados por el autor y que leen de consuno contra el manuscrito; la hipótesis de una revisión del texto después de 1558 resulta menos verosímil ${ }^{17}$. En la misma dirección apunta el análisis de algunas variantes, como la del v. 76, seguramente hipermétrico en $H$. O la del v. 100, que en los impresos salva una leve dificultad de lectura causada por la distancia que media en $H$ entre el adjetivo ajeno y el sustantivo al que se refiere (reino); y lo hace, además, recurriendo por necesidades métricas a una forma verbal (quies por quieres) que no era rara en la época, pero cuya inserción parece más propia de un autor que no de un copista.

Así las cosas, la cuestión central es si realmente hay que reconocer en $H$ el testimonio representativo de una redacción distinta del poema, y en qué grado. La práctica poética del lusitano lo hace posible y el análisis de las variantes le da, como hemos visto, cierta verosimilitud. Pero no puede descartarse, por ejemplo, que la copie derive en última instancia de una memorización, ejecutada sea por el propio autor, sea por un aficionado y buen conocedor de la poesía religiosa del momento. En estas condiciones, la prudencia crítica se impone.

En cualquier caso, entiendo que los datos aquí espigados constituyen un botón de muestra suficiente para construir la imagen de Montemayor como un poeta especialmente interesado por la revisión de sus versos y cuya gran fortuna editorial le permitió dejar constancia de ello en sucesivas impresiones de sus obras.

17 Empleo la fecha de 1558, o sea la de publicación del Segundo cancionero spiritual, de manera convencional, ya que el libro lleva una escueta aprobación eclesiástica expedida por [Philippus de] Almaras canonicus antuerpiensis en 1557. 